University of Nebraska - Lincoln

DigitalCommons@University of Nebraska - Lincoln

USDA Forest Service / UNL Faculty Publications U.S. Department of Agriculture: Forest Service -National Agroforestry Center

2008

\title{
The influence of conifer forest canopy cover on the accuracy of two individual tree measurement algorithms using lidar data
}

\author{
Michael J. Falkowski \\ University of Idaho, Falk4587@uidaho.edu \\ Alistair M.S. Smith \\ University of Idaho, alistair@uidaho.edu \\ Paul Gessler \\ University of Idaho, paulg@uidaho.edu \\ Andrew T. Hudak \\ Rocky Mountain Research Station, ahudak@fs.fed.us \\ Lee A. Vierling \\ University of Idaho, leev@uidaho.edu \\ See next page for additional authors
}

Follow this and additional works at: https://digitalcommons.unl.edu/usdafsfacpub

\begin{abstract}
Falkowski, Michael J.; Smith, Alistair M.S.; Gessler, Paul; Hudak, Andrew T.; Vierling, Lee A.; and Evans, Jeffery S., "The influence of conifer forest canopy cover on the accuracy of two individual tree measurement algorithms using lidar data" (2008). USDA Forest Service / UNL Faculty Publications. 185. https://digitalcommons.unl.edu/usdafsfacpub/185
\end{abstract}

This Article is brought to you for free and open access by the U.S. Department of Agriculture: Forest Service -National Agroforestry Center at DigitalCommons@University of Nebraska - Lincoln. It has been accepted for inclusion in USDA Forest Service / UNL Faculty Publications by an authorized administrator of DigitalCommons@University of Nebraska - Lincoln. 
Authors

Michael J. Falkowski, Alistair M.S. Smith, Paul Gessler, Andrew T. Hudak, Lee A. Vierling, and Jeffery S. Evans 


\title{
The influence of conifer forest canopy cover on the accuracy of two individual tree measurement algorithms using lidar data
}

\author{
Michael J. Falkowski, Alistair M.S. Smith, Paul E. Gessler, \\ Andrew T. Hudak, Lee A. Vierling, and Jeffery S. Evans
}

\begin{abstract}
Individual tree detection algorithms can provide accurate measurements of individual tree locations, crown diameters (from aerial photography and light detection and ranging (lidar) data), and tree heights (from lidar data). However, to be useful for forest management goals relating to timber harvest, carbon accounting, and ecological processes, there is a need to assess the performance of these image-based tree detection algorithms across a full range of canopy structure conditions. We evaluated the performance of two fundamentally different automated tree detection and measurement algorithms (spatial wavelet analysis (SWA) and variable window filters (VWF)) across a full range of canopy conditions in a mixed-species, structurally diverse conifer forest in northern Idaho, USA. Each algorithm performed well in low canopy cover conditions ( $<50 \%$ canopy cover), detecting over $80 \%$ of all trees with measurements, and producing tree height and crown diameter estimates that are well correlated with field measurements. However, increasing tree canopy cover significantly decreased the accuracy of both SWA and VWF tree measurements. Neither SWA nor VWF produced tree measurements within $25 \%$ of field-based measurements in high canopy cover (i.e., canopy cover $>50 \%$ ) conditions. The results presented herein suggest that future algorithm development is required to improve individual tree detection in structurally complex forests. Furthermore, tree detection algorithms such as SWA and VWF may produce more accurate results when used in conjunction with higher density lidar data.
\end{abstract}

Résumé. Les algorithmes de détection d'arbres individuels peuvent fournir des mesures précises de la localisation des arbres individuels, du diamètre de la couronne (à partir de photographies aériennes et de données lidar) et de la hauteur des arbres (à partir de données lidar). Cependant, pour que les algorithmes puissent être utiles pour la gestion des forêts dans le contexte de la récolte du bois, de la comptabilité du carbone forestier et des processus écologiques, il est nécessaire d'évaluer les performances de ces algorithmes de détection d'arbres basés sur les images pour une grande diversité de conditions de structure du couvert. Nous évaluons la performance de deux algorithmes fondamentalement différents de détection et de mesure automatisées d'arbres (l'analyse spatiale en ondelettes (ASO) et le filtrage par fenêtre mobile (« VWF, variable window filters »)) pour une gamme complète de conditions du couvert, dans une forêt mixte structuralement diversifiée de conifères dans le nord de l'Idaho, aux États-Unis. Chacun des algorithmes a bien performé dans des conditions de couvert faible (couvert de $<50 \%$ ), permettant de détecter plus de $80 \%$ de tous les arbres mesurés et de produire des estimations de hauteur d'arbre et de diamètre de couronne qui sont bien corrélées avec les mesures de terrain. Cependant, l'accroissement du couvert d'arbres diminue de façon significative la précision des mesures d'arbres dérivées des algorithmes ASO et VWF. Ni ASO ni VWF n'ont donné de mesures d'arbres supérieures à $25 \%$ comparativement aux mesures de terrain dans des conditions de couvert dense (c.-à-d. couvert $>50 \%$ ). Les résultats présentés dans cet article suggèrent que des développements additionnels sont nécessaires au niveau des algorithmes pour améliorer la détection d'arbres individuels dans les forêts structuralement plus complexes. De plus, les algorithmes de détection d'arbres, tels que ASO et VWF, peuvent produire des résultats plus précis lorsqu'ils sont utilisés conjointement avec des données lidar à plus haute densité.

[Traduit par la Rédaction]

\section{Introduction}

Accurate inventories of forest resources are of great economic and ecological importance to resource management agencies and private forest industries. Forest inventories conducted in regions that contain vast expanses of forest typically require significant expenditure of time and money. In an attempt to reduce costs, land managers often augment traditional forest inventory data

Received 19 February 2008. Accepted 8 September 2008. Published on the Canadian Journal of Remote Sensing Web site at http://pubs.nrc-cnrc.gc.ca/cjrs on XX XXXX 2008.

M.J. Falkowski, ${ }^{1}$ A.M.S. Smith, and P.E. Gessler. University of Idaho, Department of Forest Resources, 675 W. 6th Street, Moscow, ID 83844 , USA.

A.T. Hudak and J.S. Evans. Rocky Mountain Research Station, USDA Forest Service, 1221 S. Main Street, Moscow, ID 83843, USA.

L.A. Vierling. University of Idaho, Department of Rangeland Ecology and Management, 675 W. 6th Street, Moscow, ID 83844, USA.

${ }^{1}$ Corresponding author (e-mail: falk4587@uidaho.edu). 


\section{Pagination not final/Pagination non finale}

Vol. 34, Suppl. 2, 2008

with forest measurements derived from high spatial resolution remotely sensed data collected across large spatial extents. Historically, analog aerial photography has provided a means to manually measure many forest attributes including stand density, crown diameter, crown closure, and tree height (e.g., Spurr, 1948; Hagan and Smith, 1986; Biggs, 1991; Fensham et al., 2002). However, manual photo interpretation techniques are often time consuming and highly subjective, limiting the practicality of measuring individual tree dimensions from analog aerial photography (McRoberts et al., 2002; Zagalikis et al., 2005). More recently, high spatial resolution digital remote sensing data (e.g., IKONOS, QuickBird, and light detection and ranging (lidar)) have been used in combination with automated processing algorithms to detect and measure individual tree dimensions (Fournier et al., 1995; Gougeon, 1995; Asner et al., 2003; Wulder et al., 2004; Falkowski et al., 2006; Strand et al., 2006; Popescu, 2007).

Tree measurements derived via automated analysis of remotely sensed data have provided a means to rapidly estimate many forest attributes including tree biomass and diameter distributions across wide extents (Palace et al., 2008; Popescu, 2007) and to quantify carbon fluxes resulting from decadalscale tree encroachment (Strand et al., 2008). A variety of techniques have been developed to automatically detect and measure individual trees from remotely sensed data (Palenichka and Zaremba, 2007). Some of the most widely applied methods include $(i)$ feature matching (Greenberg et al., 2006), (ii) local maximum filtering (Wulder et al., 2004), (iii) object-based methods (Wang et al., 2004; Strand et al., 2006; Palenichka and Zaremba, 2007), (iv) variable window filters (VWF) (Popescu and Wynne, 2004; Popescu, 2007), and (v) image segmentation (Chubey et al., 2006; Chen et al., 2006; Hyyppä et al., 2001, Leckie et al., 2003).

Recent studies have presented and evaluated a novel objectbased algorithm for locating and measuring individual trees from remotely sensed data. This technique, termed spatial wavelet analysis (SWA), employs a two-dimensional (2D) wavelet transform to automatically extract the location and size (i.e., tree height and crown diameter) of individual trees from high resolution remotely sensed data (Falkowski et al., 2006; Garrity et al., 2008; Smith et al., 2008; Strand et al., 2006; 2008). The SWA tree detection and measurement algorithm is fundamentally different to many previously published approaches. First and foremost, SWA is inherently multiscale, enabling the detection and measurement of objects with characteristic shapes (i.e., trees) across a range of different sizes, with limited user input. In contrast, many popular tree detection algorithms such as image segmentation (e.g., Persson et al., 2002) or image filtering (e.g., Wang et al., 2004) must be applied at different scales in order to detect and measure trees of varying sizes. Secondly, SWA does not require a priori information regarding stand or tree characteristics (e.g., empirical tree height /crown diameter relationships). This is in direct contrast to VWF algorithms, which employ empirical relationships or other functions to determine the appropriate image filter sizes for isolating individual trees (Popescu and
Wynne, 2004; Chen et al., 2006), and to feature matching methods, which extract individual trees by matching templates of a fixed known size and shape to image objects (i.e., individual trees) (Greenberg et al., 2006).

Falkowski et al. (2006) determined the efficacy of the SWA algorithm by comparing lidar-based SWA tree measurements to field-based tree measurements, as well as to lidar-based tree measurements derived from a VWF algorithm (Popescu and Wynne, 2004). SWA and VWF provided comparable measurements of individual tree heights. However, due to a weak species-specific relationship between tree height and crown diameter across their study area, Falkowski et al. (2006) demonstrated that SWA provided more accurate estimates of tree crown diameter when compared with crown diameter estimates from the VWF algorithm. The study conducted by Falkowski et al. (2006) was limited in that it only evaluated the two algorithms in open canopy conditions (i.e., canopy cover $<50 \%$ ), where potential problems arising from high tree density and crown overlap would be minimal. However, a major shortcoming of many automatic tree extraction techniques is that their accuracy is largely dependent upon the structural complexity and density of forest stands; high detection accuracy is attained in open single-story stands, whereas comparatively lower accuracy is attained in closed multistory stands (Maltamo et al., 2004). This is due to the fact that trees growing closely together often have overlapping or interlocking crowns, making it difficult to isolate individual trees. Furthermore, as forest canopy cover increases, trees in subdominant (i.e., intermediate or suppressed) canopy cohorts become occluded by the overstory forest canopy, leading to low tree detection rates in these cohorts (Chen et al., 2006; Hyyppä et al., 2001; Persson et al., 2002; Wang et al., 2004). Although numerous studies have discussed these limitations, few have directly evaluated how increasing canopy complexity influences the accuracy of tree detection and measurement algorithms. For such methods to be truly useful for operational forest inventory, the accuracy of automated tree detection and measurement algorithms must be quantified across a full range of canopy structure conditions. Therefore, the objective of this current study is to build upon the previous works of Falkowski et al. (2006) and Popescu and Wynne (2004) by evaluating the accuracy of the SWA and VWF algorithms across a full range of conifer forest canopy structure conditions. Since canopy cover is directly related to individual tree crown overlap as well as the probability of subdominant trees being occluded by overstory trees, we assessed the accuracy of the SWA and VWF algorithms across a gradient of canopy cover (0\%-100\% canopy cover). Algorithm performance was evaluated by quantifying omission and commission errors related to tree detection. Furthermore, the accuracy of the lidar-derived individual tree measures (height and crown diameter) derived using both automated techniques was determined through comparison with field reference measurements. In terms of tree location, tree height, and crown diameter accuracies, we hypothesized that the performance of the SWA and VWF algorithms is inversely proportional to forest canopy cover. 


\section{Pagination not final/Pagination non finale}

Canadian Journal of Remote Sensing / Journal canadien de télédétection

\section{Methods}

\section{Study area and sample design}

This study was conducted on the Palouse Range (previously called Moscow Mountain), which lies $9 \mathrm{~km}$ northeast of the city of Moscow in north-central Idaho, USA (latitude $46^{\circ} 44^{\prime} \mathrm{N}$, longitude $\left.116^{\circ} 58^{\prime} \mathrm{W}\right)$. The Palouse Range is approximately 30000 ha in area and comprises a mixed-conifer temperate forest surrounded by an agricultural matrix. Dominant tree species on the Palouse Range include Pseudotsuga menziesii (PSME), Abies grandis (ABGR), Thuja plicata (THPL), and Larix occidentalis (LAOC). Other less common species occurring throughout the study area include Pinus ponderosa, Pinus contorta, Pinus monticola, and Picea engelmannii. The land on the Palouse Range is primarily owned by private timber companies; however, there are parcels of public land and private non-timber production land scattered throughout. The wide range of management objectives of each landowner, coupled with the region's complex topography, has created a forest that is diverse in both forest structure and species composition.

Eighty-three 0.04 ha forest inventory plots were located and sampled across the Palouse Range via a stratified sampling design (Falkowski et al., 2005; Pocewicz et al., 2004). The sampling design incorporated elevation, solar insolation, and leaf area index gradients as strata, to ensure that the full range of forest community types and canopy conditions existing across the Palouse Range were sampled. Once located, the position of each forest inventory plot was precisely located by logging at least 150 global positioning system (GPS) points at each plot center with a Trimble ProXR GPS. After applying a differential correction, each plot location had a threedimensional precision of $\pm 0.8 \mathrm{~m}$ in the horizontal plane and $\pm 1.1 \mathrm{~m}$ in the vertical plane. Following GPS data collection, diameter at breast height (DBH), species, and distance and bearing from plot center (i.e., location) were recorded for every tree or snag $\geq 2.7 \mathrm{~cm} \mathrm{DBH}$ within the 0.04 ha forest inventory plot. Individual tree heights and crown diameters were also measured for a subsample of trees within the inventory plot. During this subsampling procedure, the plot was partitioned into four quadrants (NW, NE, SW, and SE). A laser rangefinder (Impulse 200, Laser Technology Inc., Englewood, Colo.) was then used to measure the height and crown diameter of trees with the largest and smallest DBH for each species within each quadrant. Plot-level canopy cover was estimated by averaging four spherical densitometer measurements taken at the north, south, east, and west edges of each inventory plot. Crown classes (dominant, codominant, intermediate, or suppressed) (Helms, 1998) were assigned to distinct canopy cohorts at the plot level. The crown class of each cohort was based upon the relative, plot-level canopy position of the majority of trees within a particular cohort. Following data collection, missing tree heights were predicted based upon species-specific heightdiameter equations embedded within the forest vegetation simulator growth and yield model (Crookston and Dixon,
2005). See Falkowski et al. (2005) for a more detailed description of the study area, sampling design, and field data collection procedures.

\section{Lidar acquisition and processing}

Lidar data (1.95 $\mathrm{m}$ nominal post spacing) were acquired across the study area in the summer of 2003 (Leica ALS 40 System; Horizon's, Inc., Rapid City, S.D.). The system operated at a wavelength of $1064 \mathrm{~nm}$ and was flown at approximately $2500 \mathrm{~m}$ elevation above mean terrain. Once acquired, the lidar flight lines were trimmed to remove returns with a scan angle greater than $18^{\circ}$ while maintaining complete coverage across the study area. The raw lidar data were then classified into ground and non-ground returns via the multiscale curvature classification algorithm (Evans and Hudak, 2007). A high resolution digital elevation model (DEM) was interpolated from the ground returns. The interpolated DEM had root mean square errors (RMSEs) of 0.306 and $0.166 \mathrm{~m}$ in high canopy cover and low canopy cover forests, respectively (Evans and Hudak, 2007). Following DEM generation, the height above ground surface was calculated for each nonground lidar return through DEM subtraction. Rasterized canopy height models (CHMs) were created at a spatial resolution of $0.5 \mathrm{~m}$ for each of the selected forest inventory plots from the non-ground lidar returns using a naturalneighbor algorithm.

\section{Locating and measuring trees with spatial wavelet analysis}

SWA was applied to each lidar-derived CHM to automatically identify the location $(x, y)$ of each tree and estimate their crown diameters and heights. SWA has been shown to be a robust individual tree detection and measurement method in both aerial photography (Strand et al., 2006; 2008; Garrity et al., 2008; Smith et al., 2008) and lidar (Falkowski et al., 2006) datasets. The SWA algorithm, which is described in detail elsewhere (Strand et al., 2006; Falkowski et al., 2006; Smith et al., 2008), convolves a series of sequentially larger 2D Mexican hat wavelet functions with the lidar-derived CHM. The algorithm, which implements a discrete approximation of the continuous wavelet transformation, uses the Mexican hat wavelet basis function because its shape is similar to the shape of individual conifer tree crowns (Falkowski et al., 2006). When the horizontal dimension of the $2 \mathrm{D}$ wavelet (i.e., wavelet dilation scale) is approximately equal to the horizontal size of an object within the CHM (i.e., an individual tree diameter), it is retained. This wavelet size corresponds to the crown diameter of an individual tree in the CHM at location $x, y$. After all possible wavelet sizes (1-15 m) have passed over the CHM, the maximum height value within each retained wavelet diameter is extracted. This height value represents an estimation of the height of the individual tree at location $x, y$ (Figure 1). 


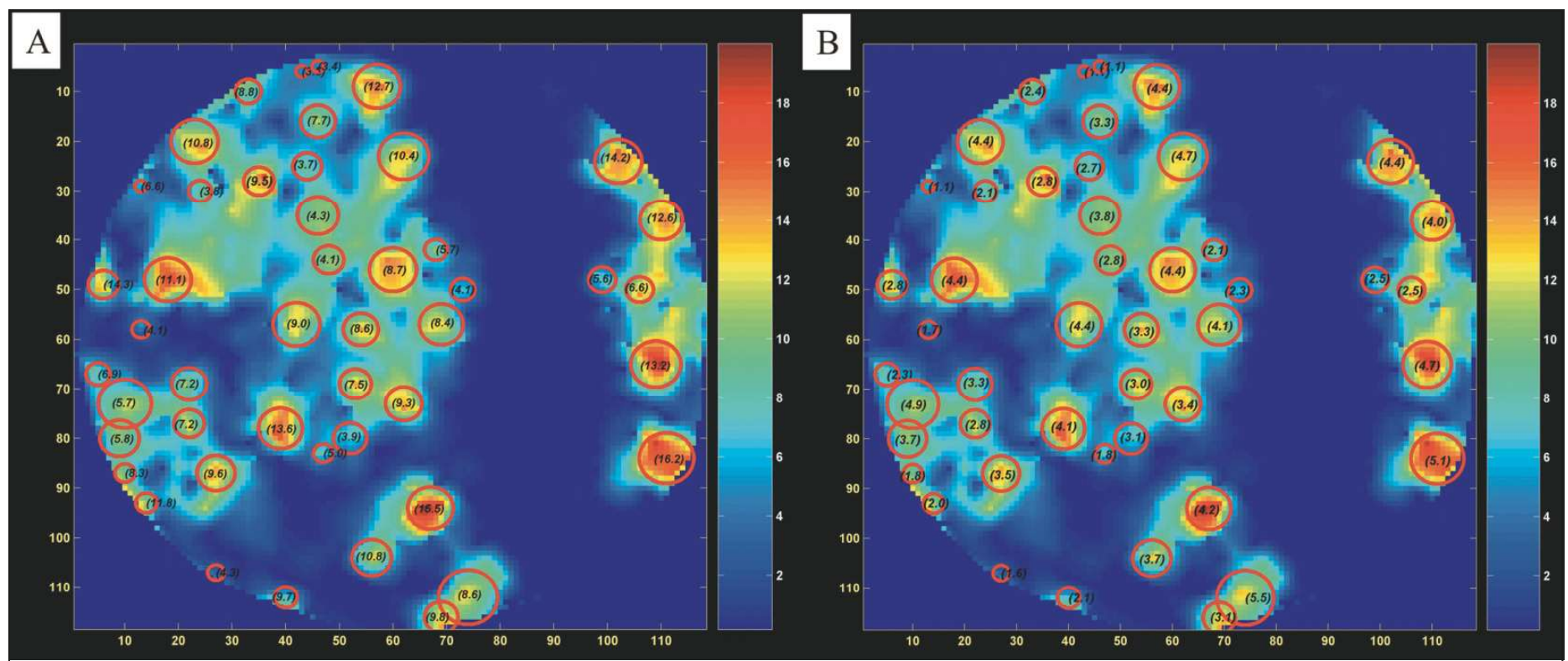

Figure 1. Graphical output from the spatial wavelet analysis algorithm. A lidar canopy height model with wavelet-derived tree crown diameters displayed as red circles. The text within each red circle corresponds to individual tree crown diameters (A) and tree heights (B) in meters. The color ramp represents the height of the canopy height model in meters.

\section{Locating and measuring trees with variable window filters}

The VWF algorithm (Popescu and Wynne, 2004) was also used to identify the location and estimate the size of individual trees within each CHM. The VWF algorithm, which is currently executed as the TreeVaW software program (Popescu, 2008), determines the location of each tree by passing a series of local maxima (LM) filters over the CHM. The size of each LM filter is a function of the height of each pixel within the lidar CHM, and is calculated based upon an allometric relationship between tree height and tree crown diameter. The location and values of each identified LM correspond to the location and height of individual trees, respectively, and the size of the LM filter corresponds to the crown diameter for each identified tree (Popescu and Wynne, 2004).

Because the VWF algorithm relies upon allometric data for successful operation, it was necessary to adapt the algorithm for the Palouse Range study area by modifying the equation it implements to estimate crown diameter from tree height. However, the relationship between tree height and crown diameter for trees occurring on the Palouse Range is speciesspecific (Figure 2). When calculated across all tree species in the forest inventory dataset, the strongest relationship between tree crown diameter and tree height is a linear function described by the following equation:

$c d=0.14 h+2.56$

where $c d$ is the tree crown diameter, and $h$ is the tree height in meters. This linear function has an $r^{2}$ of 0.34 and a RMSE of $1.31 \mathrm{~m}$.

\section{SWA and VWF evaluation}

For the purpose of this study, the inventory plots were partitioned into four canopy cover strata $(0-25 \%, 25 \%-50 \%$, $50 \%-75 \%$, and $75 \%-100 \%$ ). Two separate random samples were then taken; one for estimating errors of omission and commission, and one for estimating the accuracy of tree measurement from the SWA and VWF algorithms. Errors of omission and commission were estimated from a random subset of forest inventory plots within each of the five canopy cover strata. Since plots with low canopy cover typically have fewer trees than plots with higher canopy cover, the random selection process was repeated until there were approximately 30 trees within each stratum. For the second random sample (to quantify VWF and SWA tree measurement accuracy), 30 individual trees with field-measured heights and crown diameters were randomly selected from each canopy cover stratum (120 total trees). The range in tree heights and crown diameters for the 120 selected trees was $5.12-36.8 \mathrm{~m}$ and 1.60 $14.55 \mathrm{~m}$, respectively (mean tree height $=16.65 \mathrm{~m}$; mean tree crown diameter $=4.96 \mathrm{~m})$. Seventy-two of the 120 selected trees were in dominant canopy cohorts, 29 were in codominant canopy cohorts, and 19 were in subdominant canopy cohorts (i.e., intermediate or suppressed canopy cohorts). Figure 3 displays the distribution of tree heights and crown diameters within each canopy cover stratum as well as by the four dominant tree species. Table 1 presents tree density statistics and canopy cover distributions across all canopy cover strata.

\section{Errors of omission and commission}

Field-measured tree locations within each selected plot (from the first random sample described above) were paired with corresponding SWA and VWF tree locations based upon 


\section{Pagination not final/Pagination non finale}

Canadian Journal of Remote Sensing / Journal canadien de télédétection
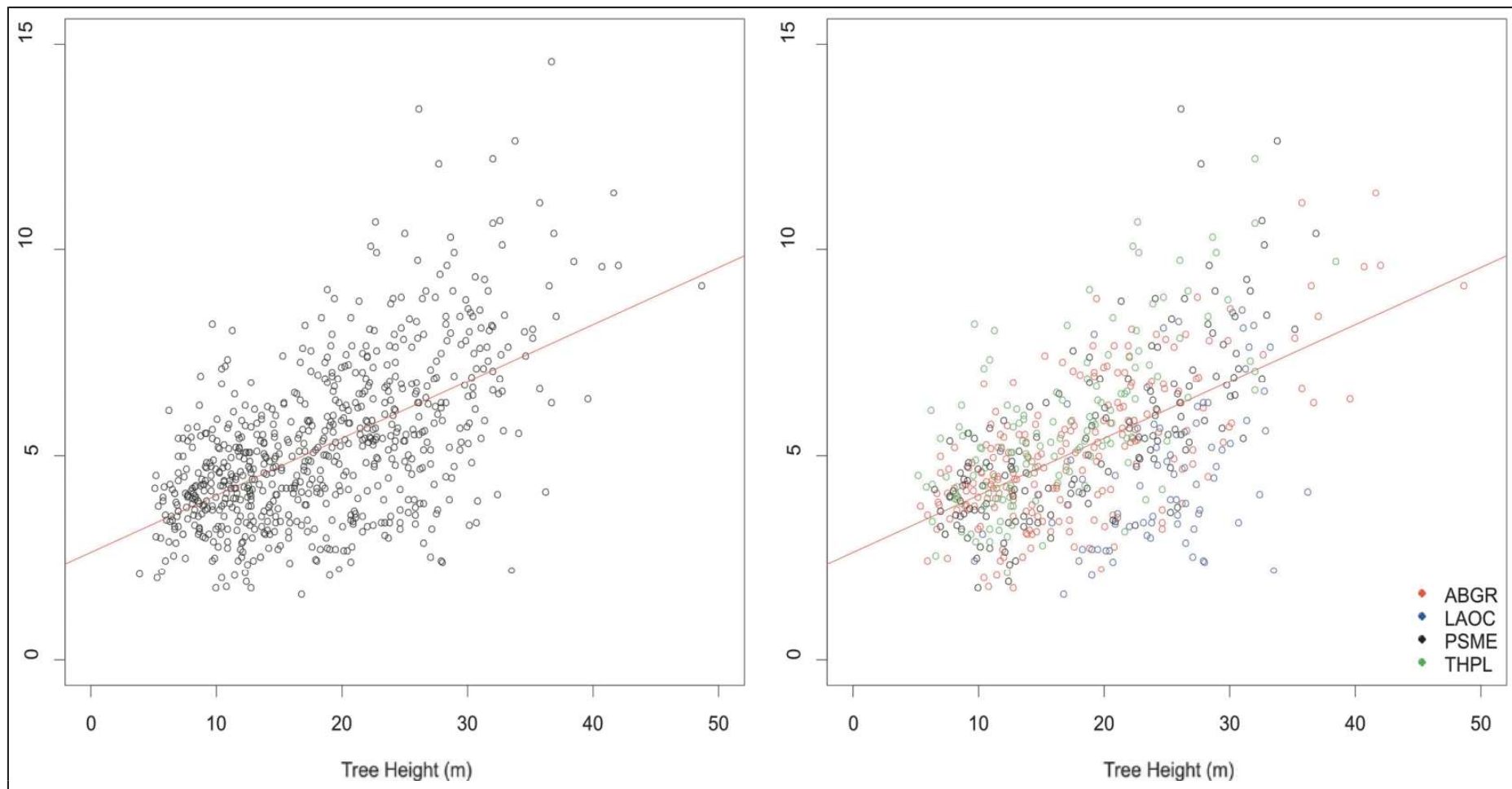

Figure 2. Height-crown diameter relationship for the trees on the Palouse Range. (Left) A scatterplot of height-crown diameter for all 10 tree species within the study area. (Right) A scatterplot displaying only four of the most common species. The red line is the linear model defined by Equation (2).

proximity of the estimated field-measured tree to SWA and VWF locations with similar tree heights. In most cases, the field-measured tree location was within the boundary of a crown diameter estimated by SWA or VWF. However, when a field-measured tree location was not within an estimated crown diameter, a limiting distance threshold was implemented. Specifically, field-measured tree locations of greater than $2.5 \mathrm{~m}$ outside the edge of an estimated crown diameter boundary were not assigned to that particular SWA or VWF identified tree. A distance of $2.5 \mathrm{~m}$ was chosen because it corresponds to the average crown radius of dominant and codominant trees within the dataset. When a field-measured tree could not be successfully paired with a tree identified by the SWA or VWF algorithms, an error of omission was recorded. Errors of commission were recorded when there were no field-measured tree locations near trees identified by SWA or VWF. Two sets of omission and commission errors were calculated; one set including all trees within the inventory plots, and one set only including trees from dominant and codominant canopy cohorts.

\section{Tree height and crown diameter accuracy}

The 120 trees selected in the second random sample were paired with corresponding field-measured trees via the same process described above. The accuracy of tree heights and crown diameters for each tree measurement algorithm (i.e., SWA and VWF) was then determined through a comparison with field-measured tree heights and crown diameters. The estimated tree dimensions were statistically compared within each of five canopy cover strata $(0 \%-25 \%, 25 \%-50 \%, 50 \%-$ $75 \%, 75 \%-100 \%$, as well as $0 \%-100 \%)$ using Pearson's correlation coefficients $(r)$, RMSEs, and mean difference (MD; Equation 2) statistics. MD can be described as

$\mathrm{MD}=\operatorname{Mean}\left(Y_{j}-Y_{i}\right)$

where $Y_{j}$ is the estimated tree measurement and $Y_{i}$ is the fieldbased tree measurement. The percentage of trees detected was also calculated within each canopy cover stratum.

Equivalence tests were used to determine if the SWA- and VWF-based tree measurements were similar (i.e., equal) to field-measured tree dimensions. We also assessed whether the similarity of tree measurements changed as a function of tree canopy cover. Equivalence tests, which are widely applied in the field of biostatistics (Wellek, 2003; Robinson et al., 2005), are used to test the null hypothesis of "no significant difference" between two sample populations $\left(H_{0}\right.$ : there is a difference between sample populations; $H_{1}$ : the sample populations are equal). We chose a regression-based equivalence test (Robinson et al., 2005) to test for intercept equality (i.e., the mean of SWA or VWF measurements is equal to the mean of field-based measurements) and slope equality to 1 (i.e., if the pairwise tree measurements are equal, the regression will have a slope of 1$)$. The region of equivalence was set to $\pm 25 \%$ (of the mean) for the intercept $\left(b_{0}\right)$ and $\pm 25 \%$ for the slope $\left(b_{1}\right)$. The null hypothesis of dissimilarity between SWA or VWF tree measurements and field-based tree 


\section{Pagination not final/Pagination non finale}

Vol. 34, Suppl. 2, 2008
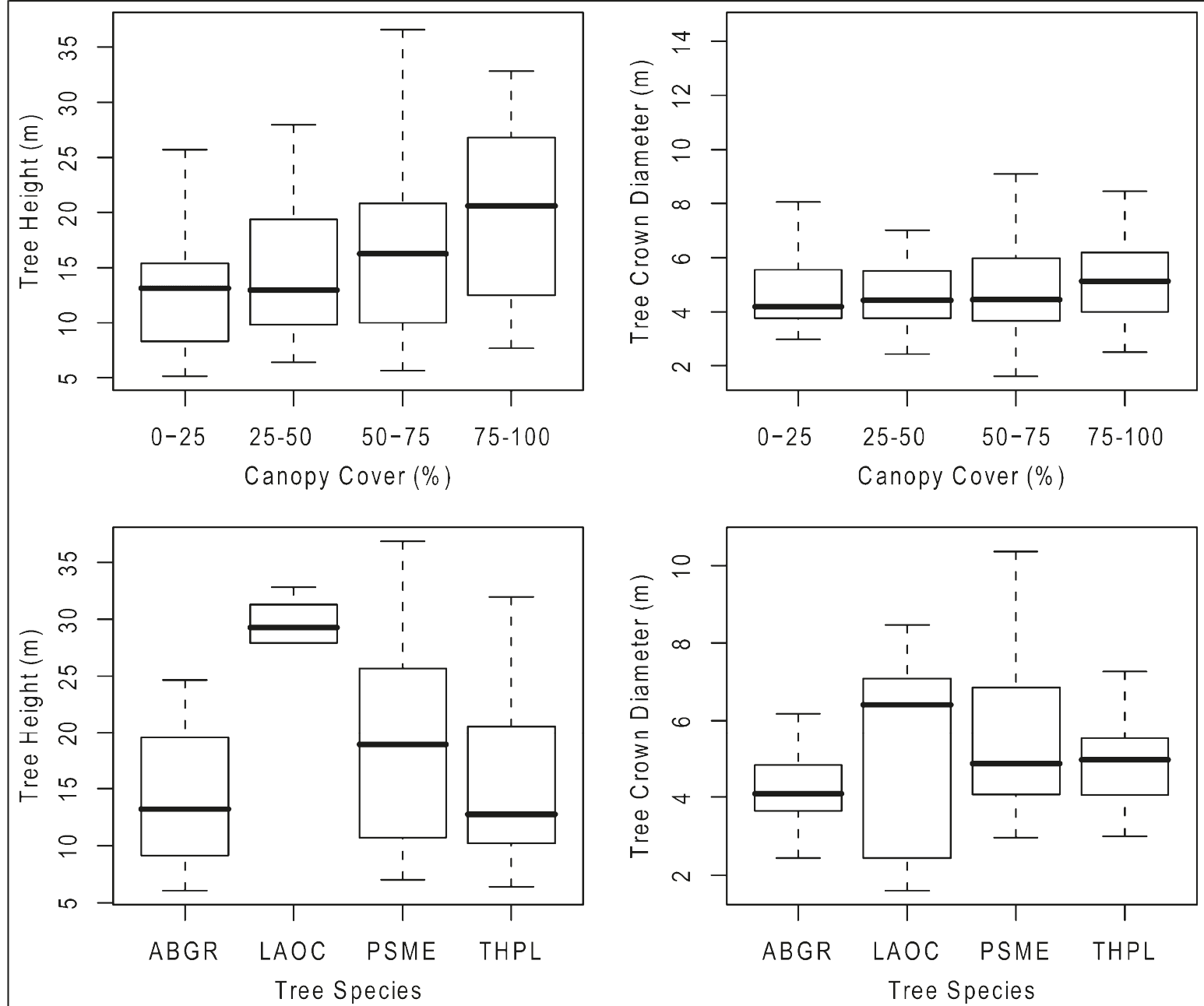

Figure 3. Boxplots displaying the distribution of tree heights and crown diameters by canopy cover class and by species.

measurements is rejected if the interval of equivalence $( \pm 25 \%)$ contains two joint one-sided 95\% confidence intervals $(\alpha=$ $0.05)$ for the slope or intercept. All statistical analyses were conducted in the freeware statistical software package, R (R Development Core Team, 2007). Equivalence testing was conducted with the equivalence package within R (Robinson, 2007).

\section{Results}

\section{Errors of omission and commission}

When considering dominant, codominant, and subdominant canopy cohorts, the VWF algorithm had an omission error of $35 \%$ across the entire dataset (0\%-100\% canopy cover), whereas the SWA algorithm had an omission error of $43 \%$ (Table 2). Both algorithms had omission errors of less than $10 \%$ in the lowest canopy cover strata $(0 \%-25 \%)$. However, as cover increased from 0 to $100 \%$, the number of trees correctly detected by each algorithm decreased. The VWF algorithm had lower omission errors than the SWA algorithm within all canopy cover strata. Commission errors in the 0\%-100\%
Table 1. Tree density by canopy cover strata and total land area within each strata across the Palouse Range study area.

\begin{tabular}{lclll}
$\begin{array}{l}\text { Canopy } \\
\text { cover }(\%)\end{array}$ & Mean & $\begin{array}{l}\text { Standard } \\
\text { deviation }\end{array}$ & Range & $\begin{array}{l}\text { Land area } \\
\text { (ha) }\end{array}$ \\
\hline $0-25$ & 40 & 19 & 57 & 11408 \\
$25-50$ & 107 & 13 & 35 & 3003 \\
$50-75$ & 154 & 16 & 57 & 5984 \\
$75-100$ & 225 & 19 & 62 & 10985 \\
\hline
\end{tabular}

Note: Units are trees per ha.

canopy cover strata were $6 \%$ and $15 \%$ for the SWA and VWF algorithms, respectively. The highest rates of commission errors occurred in the $0 \%-25 \%$ and $25 \%-50 \%$ canopy cover strata for the SWA and VWF algorithms, respectively. Both methods had a $3 \%$ commission error in the highest canopy cover strata (75\%-100\%; Table 2).

When considering only dominant and codominant canopy cohorts, the VWF algorithm had an omission error of $29 \%$ across the entire dataset ( $0 \%-100 \%$ canopy cover), whereas the SWA algorithm had an omission error of $37 \%$ (Table 3). VWF 


\section{Pagination not final/Pagination non finale}

Canadian Journal of Remote Sensing / Journal canadien de télédétection

Table 2. Omission and commission errors for the spatial wavelet analysis (SWA) and variable window filters (VWF) within each canopy cover stratum.

\begin{tabular}{|c|c|c|c|c|c|c|c|c|}
\hline \multirow{3}{*}{$\begin{array}{l}\text { Canopy } \\
\text { cover } \\
(\%)\end{array}$} & \multicolumn{4}{|c|}{ All trees } & \multicolumn{4}{|c|}{ Excluding subdominant trees } \\
\hline & \multicolumn{2}{|c|}{ Omission error $(\%)$} & \multicolumn{2}{|c|}{ Commission error $(\%)$} & \multicolumn{2}{|c|}{ Omission error $(\%)$} & \multicolumn{2}{|c|}{ Commission error $(\%)$} \\
\hline & SWA & VWF & SWA & VWF & SWA & VWF & SWA & VWF \\
\hline $0-100$ & 43 & 35 & 6 & 15 & 94 & 85 & 8 & 18 \\
\hline $0-25$ & 8 & 4 & 12 & 17 & 16 & 9 & 13 & 19 \\
\hline $25-50$ & 44 & 33 & 5 & 28 & 40 & 29 & 6 & 31 \\
\hline $50-75$ & 59 & 39 & 6 & 13 & 48 & 36 & 8 & 16 \\
\hline $75-100$ & 61 & 56 & 3 & 3 & 50 & 43 & 4 & 4 \\
\hline
\end{tabular}

Table 3. Goodness-of-fit statistics between estimated and field-measured tree heights.

\begin{tabular}{|c|c|c|c|}
\hline $\begin{array}{l}\text { Canopy } \\
\text { cover }(\%)\end{array}$ & Correlation & RMSE (m) & $\mathrm{MD}(\mathrm{m})$ \\
\hline \multicolumn{4}{|c|}{ Tree height: SWA } \\
\hline $0-100$ & 0.89 & 3.96 & 0.34 \\
\hline $0-25$ & 0.99 & 1.69 & -1.07 \\
\hline $25-50$ & 0.90 & 2.33 & 0.66 \\
\hline $50-75$ & 0.84 & 4.30 & 2.14 \\
\hline $75-100$ & 0.68 & 5.93 & -0.10 \\
\hline \multicolumn{4}{|c|}{ Tree height: VWF } \\
\hline $0-100$ & 0.89 & 4.06 & -0.08 \\
\hline $0-25$ & 0.98 & 2.22 & -1.24 \\
\hline $25-50$ & 0.92 & 2.05 & -0.09 \\
\hline $50-75$ & 0.88 & 4.08 & 1.56 \\
\hline $75-100$ & 0.73 & 5.60 & -0.53 \\
\hline
\end{tabular}

Table 4. Goodness-of-fit statistics between estimated and field-measured tree crown diameters.

\begin{tabular}{|c|c|c|c|}
\hline $\begin{array}{l}\text { Canopy } \\
\text { cover }(\%)\end{array}$ & Correlation & RMSE (m) & $\mathrm{MD}(\mathrm{m})$ \\
\hline \multicolumn{4}{|c|}{ Crown diameter: SWA } \\
\hline $0-100$ & 0.50 & 1.71 & 0.21 \\
\hline $0-25$ & 0.70 & 2.02 & 0.08 \\
\hline $25-50$ & 0.38 & 1.45 & 0.56 \\
\hline $50-75$ & 0.26 & 1.81 & 0.69 \\
\hline $75-100$ & 0.22 & 1.29 & -0.52 \\
\hline \multicolumn{4}{|c|}{ Crown diameter: VWF } \\
\hline $0-100$ & 0.61 & 1.60 & -1.03 \\
\hline $0-25$ & 0.85 & 1.47 & -1.41 \\
\hline $25-50$ & 0.20 & 1.51 & -1.02 \\
\hline $50-75$ & 0.80 & 1.53 & -0.91 \\
\hline $75-100$ & 0.34 & 1.39 & -0.74 \\
\hline
\end{tabular}

had an omission error of $9 \%$ in the lowest canopy cover stratum $(0 \%-25 \%)$, whereas SWA had an omission error of $16 \%$. As cover increased from $0 \%$ to $100 \%$, the number of trees correctly detected by each algorithm decreased. Again, the VWF algorithm had lower omission errors than the SWA algorithm within all canopy cover strata. Commission errors in the $0 \%-100 \%$ canopy cover strata were $8 \%$ and $18 \%$ for the SWA and VWF algorithms, respectively. The highest rates of commission errors occurred in the $0 \%-25 \%$ and $25 \%-50 \%$ canopy cover strata for the SWA and VWF algorithms, respectively. Both methods had a $3 \%$ commission error in the highest canopy cover strata (75\%-100\%; Table 3).

\section{VWF and SWA tree height accuracy}

The SWA algorithm detected 96 of the 120 selected trees (80\%). Furthermore, using SWA, we were able to detect $97 \%$ of trees within dominant canopy cohorts, $62 \%$ of trees within codominant canopy cohorts, and $42 \%$ of tree within subdominant canopy cohorts. Using the VWF algorithm, we detected $85 \%$ of the 120 selected trees; $94 \%$ of trees within dominant canopy cohorts, $79 \%$ of trees within codominant canopy cohorts, and $58 \%$ of trees within subdominant canopy cohorts. Overall, the measurement of tree height from lidar data via the SWA $(r=0.89, \operatorname{RMSE}=3.96 \mathrm{~m})$ and VWF $(r=0.89$,
RMSE $=4.06 \mathrm{~m}$ ) algorithms produced similar results. Furthermore, changes in canopy cover had similar effects upon the accuracy of tree height measurements obtained from each method; as canopy cover increased, the accuracy of tree height measurements decreased (Table 4). In terms of mean difference, the SWA method slightly overpredicted tree height, whereas the VWF algorithm slightly underpredicted tree height across the entire sample of 120 trees $(\mathrm{MD}=0.34$ and -0.08 for SWA and VWF, respectively). Although tree canopy cover did influence the degree of bias for each method, no pattern in bias emerged across the canopy cover strata; some strata had negative MD statistics, while others exhibited positive MD statistics.

Figures $\mathbf{4}$ and $\mathbf{5}$ present results from the statistical equivalence test. A brief explanation on how to interpret the equivalence test graphs is warranted. The grey polygon represents the $\pm 25 \%$ region of equivalence for the intercept, and the red vertical bar represents a $95 \%$ confidence interval for the intercept. The mean of field-measured tree dimensions are equivalent to the SWA- or VWF-derived tree dimensions when the red vertical bar is completely within the grey polygon.

If the grey polygon is lower than the red vertical bar, the VWF or SWA measurements are biased low; if it is higher than SWA or VWF, then measurements are biased high. The grey dashed line represents the $\pm 25 \%$ region of equivalence for the slope, and the 

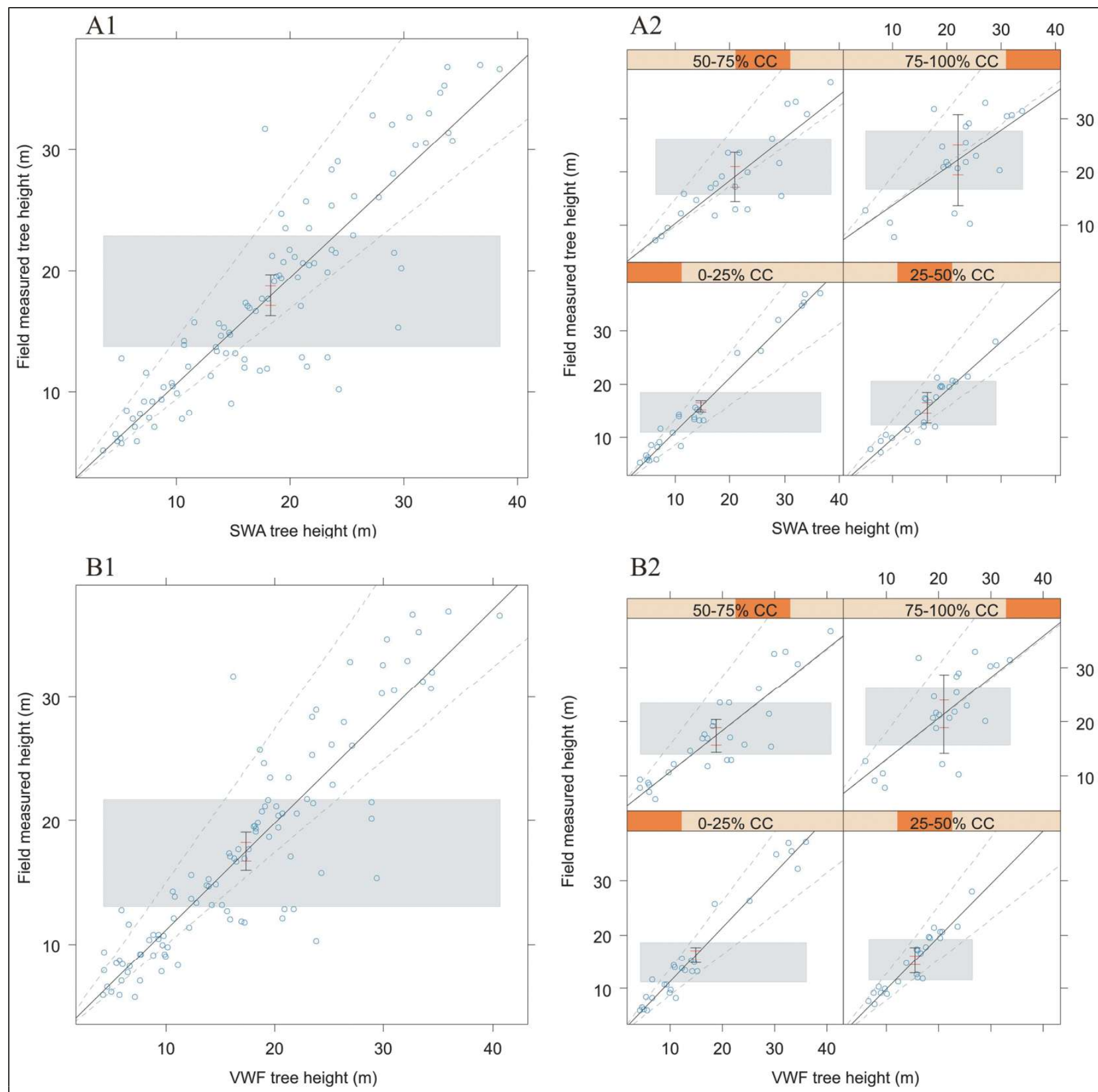

Figure 4. Equivalence test graphs for tree heights derived from the spatial wavelet analysis (SWA) algorithm (A1) and variable window filters (VWF) algorithm (B1). A2 and B2 display equivalence test graphs within each canopy cover (CC) stratum.

black vertical bar represents a $95 \%$ confidence interval for the slope. When the black vertical bar is contained completely within the grey dashed line, the pairwise measurements are equal. A bar that is wider than the region outlined by the grey dashed lines indicates highly variable predictions. The blue circles are the pairwise measurements, and the solid black line is a best-fit linear model for the pairwise measurements. Tree heights derived from the SWA and VWF methods were statistically equivalent across the entire sample of 120 trees (Figures 4A1 and 4B1). When partitioned into canopy cover strata, the methods were equivalent in the $0 \%-25 \%$ and $25 \%-$ $50 \%$ canopy cover strata, and unequivalent in the $50 \%-75 \%$ and 75\%-100\% strata (Figures 4A2 and 4B2). Further investigation of the equivalence graphs revealed much more prediction variability in the $75 \%-100 \%$ canopy cover stratum (i.e., the confidence interval of the slope (black bar) is much wider than 

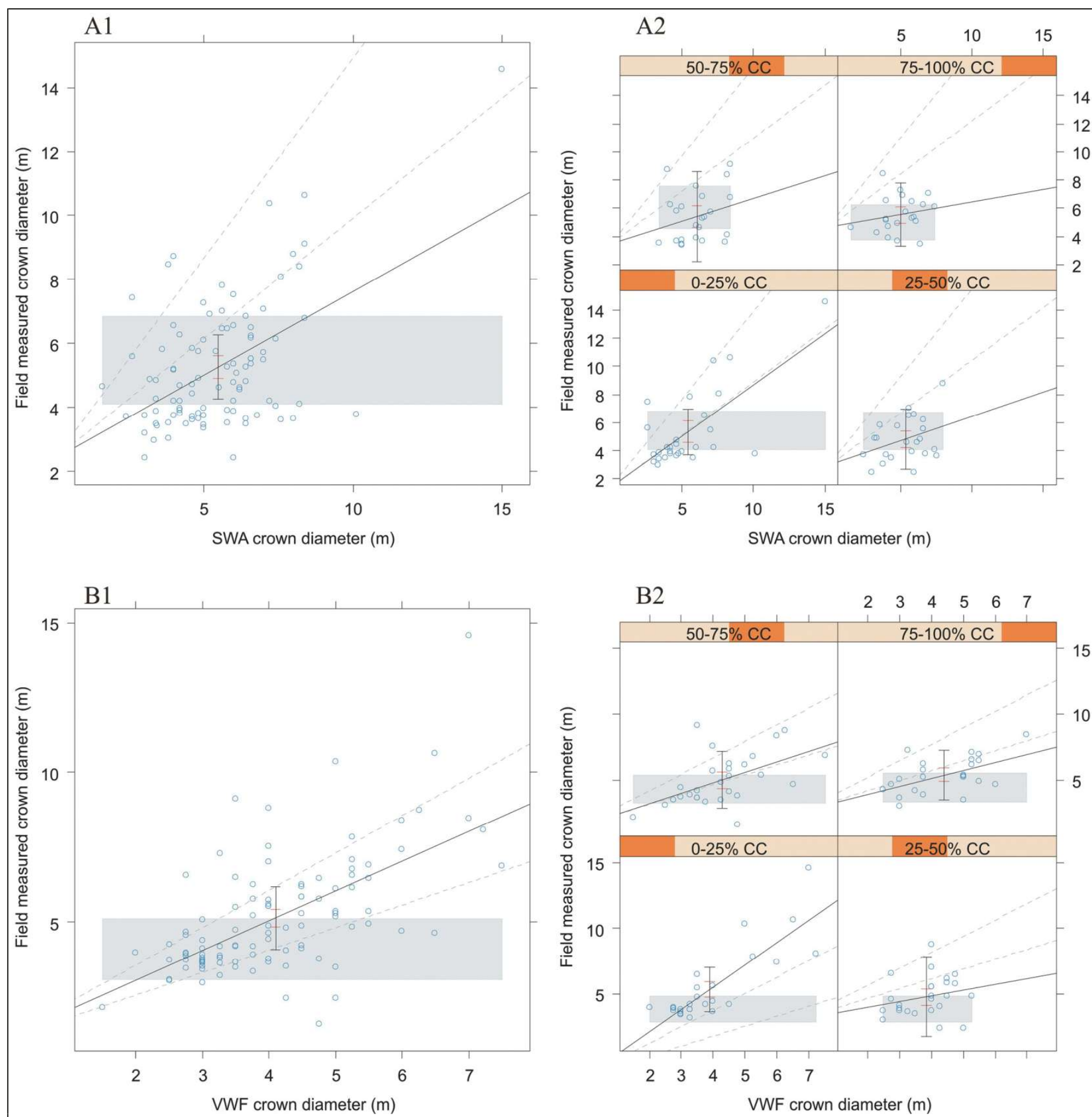

Figure 5. Equivalence test graphs for tree crown diameters derived from the spatial wavelet analysis (SWA) algorithm (A1) and variable window filters (VWF) algorithm (B1). A2 and B2 display equivalence test graphs within each canopy cover (CC) stratum.

the region of equivalence for the slope (indicated by the grey dashed lines; Figure 4)).

\section{VWF and SWA tree crown diameter accuracy}

For tree crown diameter measurements, the VWF algorithm $(r=0.61, \mathrm{RMSE}=1.60 \mathrm{~m})$ was slightly more accurate than the
SWA algorithm $(r=0.50$, RMSE $=1.71 \mathrm{~m})$ applied to all 120 trees (0\%-100\% canopy cover; Table 4$)$. The accuracy of tree crown diameter measurements extracted via the SWA algorithm decreased as canopy cover increaseed, and very low accuracies were achieved above $50 \%$ canopy cover. This pattern did not hold true for tree crown diameter measurements derived from the VWF algorithm. In general, the accuracy of 


\section{Pagination not final/Pagination non finale}

Vol. 34, Suppl. 2, 2008

VWF tree crown diameter measurements decreased with an increase in canopy cover. However, VWF crown diameter measurements in the $25 \%-50 \%$ canopy cover stratum $(r=0.20$, RMSE $=1.51 \mathrm{~m}$ ) were much lower than VWF crown diameter measurements within any other canopy cover stratum (Table 4). The MD statistic indicated that, in general, the SWA algorithm overestimates tree crown diameter, whereas the VWF algorithm underestimates tree crown diameter. Furthermore, as canopy cover increased, the bias of SWA tree crown diameter measurements tended to increase. The opposite was true for VWF tree crown diameter measurements: as canopy cover increased, VWF measurements exhibited less bias.

The mean tree crown diameter derived from the SWA algorithm was statistically equivalent to the mean fieldmeasured crown diameter for all 120 trees. However, the slope equivalence test revealed that the pairwise SWA and field crown diameter measurements are not equivalent. This relationship held true across all canopy cover strata. Furthermore, as canopy cover increased, the variability of SWA crown diameter predictions increased significantly (Figure 5). On the other hand, the pairwise VWF and field crown diameter measurements were statistically equivalent when considering all 120 selected trees. However, the means were not equivalent and exhibited a slightly low bias. When partitioned into canopy cover strata, the mean and pairwise VWF tree crown diameter measurements were not equivalent to the field-based measurements across all canopy cover strata (see Figure 5).

\section{Discussion}

Two automated algorithms (SWA and VWF) for estimating the location, height, and crown diameter of individual trees from lidar data were compared and evaluated across a full range of canopy cover conditions (0\%-100\% canopy cover). In general, tree location errors attained by the SWA and VWF algorithms were inversely proportional to forest canopy cover. In terms of omission errors, VWF outperformed SWA, especially in the $25 \%-50 \%$ and $50 \%-75 \%$ canopy cover strata. However, the SWA algorithm had fewer commission errors within most of the canopy cover strata. This was most pronounced in the $25 \%-50 \%$ canopy cover stratum, where SWA had a $23 \%-25 \%$ lower commission error as compared with VWF. The omission and commission error differences between SWA and VWF cover is not surprising, given that the SWA algorithm, in its current implementation, only considers the horizontal domain when identifying individual trees. In other words, tree detection by SWA is only a function of wavelet diameter, not height. As a result, SWA tended to detect clumped trees as one object, rather than as individuals (Figure 6). This results in an under-identification of individual trees, and fewer commission errors. Although the lidar CHM inherently includes vertical information, SWA is insensitive to tree height when determining crown diameter. High tree clumping was less of a problem for VWF, because the algorithm operates in both the vertical and horizontal domains. Since VWF identifies the location of individual trees solely

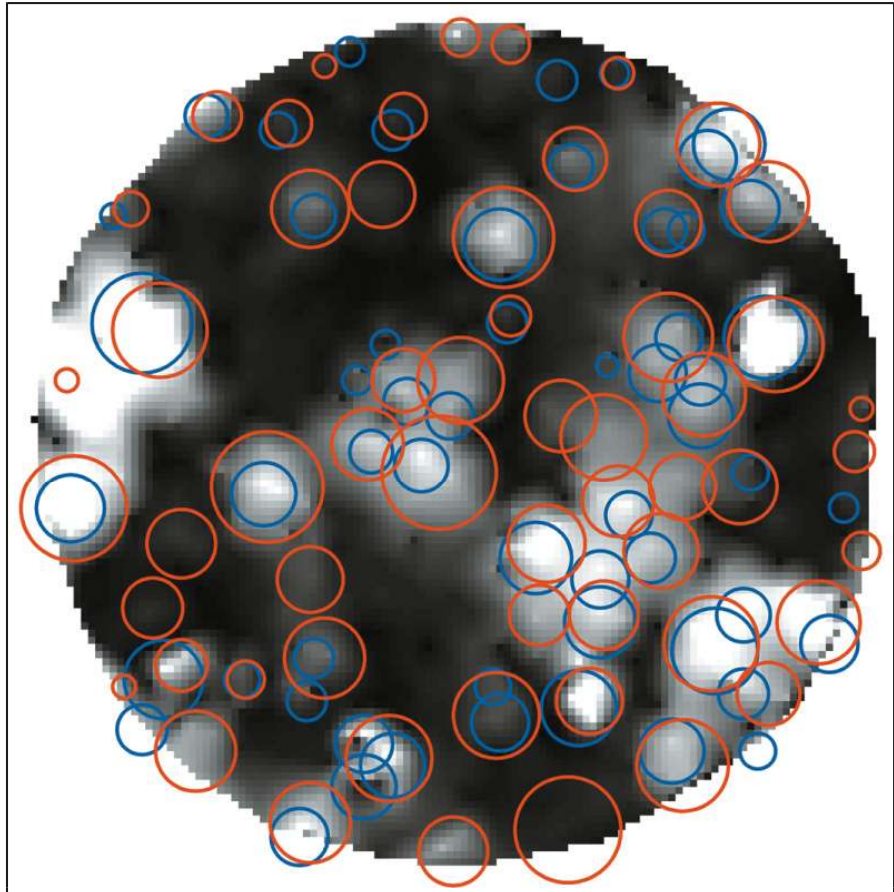

Figure 6. Lidar canopy height model with predicted crown diameters by the wavelet (red circles) and variable window filters (VWF) (blue circles) methods. When trees are clustered, spatial wavelet analysis (SWA) detects fewer trees than VWF.

based upon local maxima within a lidar CHM, clumped trees were typically identified as individuals (Figure 6). This also results in a higher rate of commission error for the VWF algorithm; local maxima algorithms may detect multiple maxima within the same tree (e.g., a tree with multiple apices, or long extending branches may be detected as more than one individual (Solberg et al., 2006)). Further research could potentially improve the SWA algorithm by developing threedimensional wavelets that take advantage of the vertical tree height information the lidar data provide.

Excluding subdominant canopy cohorts from the analysis reduced the omission errors for both algorithms. However, the improvement was more pronounced in the 75\%-100\% canopy cover stratum. Furthermore, excluding the subdominant canopy cohorts increased commission errors for both algorithms across all canopy cover strata. These results indicate that SWA and VWF were able to detect some trees in subdominant canopy cohorts, especially when canopy cover was below 75\%. Indeed, when considering the 120 trees selected for tree measurement accuracy, SWA and VWF were able to detect $42 \%$ and $58 \%$ of trees within subdominant canopy cohorts, respectively.

SWA and VWF tree height measurements display similar accuracies when compared with field measurements of tree height via goodness-of-fit statistics (i.e., correlation coefficients, RMSE, and MD). The difference in RMSEs between the tree heights derived from each method was only $10 \mathrm{~cm}$ overall, and each method had equal correlation coefficients $(r=0.89)$. Increasing canopy cover resulted in a decrease in accuracy for tree heights measured via both 


\section{Pagination not final/Pagination non finale}

Canadian Journal of Remote Sensing / Journal canadien de télédétection

methods, and the accuracy of each method was relatively low above 50\% canopy cover. Equivalence tests indicate that, although the mean of SWA and VFW height measurements were equal to the mean of field height measurements, the pairwise measurements were unequal at the $25 \%$ equivalence level above 50\% canopy cover (i.e., VWF and SWA trees heights are $>25 \%$ different than field-measured tree heights in high canopy cover conditions). The MD statistics and equivalence tests indicate that there was no consistent bias in tree height measurements across canopy cover strata. Furthermore, the equivalence test graphs indicate that above $50 \%$ canopy cover, there was a high variability in SWA and VWF measurements, and that both methods underpredicted high tree heights and overpredicted low tree heights. This result is surprising, given that previous studies have found lidar data to consistently underestimate tree heights due to laser pulse canopy penetration and the low probability of a pulse actually striking the apex of a tree (e.g., Gaveau and Hill, 2003; Maltamo et al., 2004; Falkowski et al., 2006). There are a few possible explanations for these discrepancies. First, crown dominance is likely influencing the accuracy of each method (Maltamo et al., 2004). For example, SWA or VWF may not detect trees within codominant canopy cohorts that are close to dominant trees. However, if detected, the height of the codominant tree will likely be overestimated due to crown overlap. Second, the accuracy of field-based tree height measurements is likely to be lower in high canopy cover conditions. This is due to the fact that, when measuring tree heights in the field, it is often difficult to identify the exact top of a tree in dense canopies. In such situations, the location of a tree apex may need to be approximated. Doing so incorrectly will result in either over- or underestimation of tree heights (Clark et al., 2004). The influence of GPS error is also an unquantified source of uncertainty in the current study. Previous research has shown that the accuracy of Trimble ProXR GPS units decrease with increasing canopy density. For example, a study conducted by the US Forest Service, in a similar forest type to the one presented herein, demonstrated that the error of a ProXR GPS was $2.73 \mathrm{~m}$ when collecting an average of 60 GPS positions and performing a differential correction (USDA Forest Service, 2008). Although we collected at least 150 GPS positions at each inventory plot and performed a differential correction, it is likely that the GPS plot location error increases with an increase in canopy cover. This leads to a less accurate stem map in areas with high canopy cover, ultimately making it very difficult to objectively determine if a sample tree had actually been detected in high canopy cover situations.

One additional caveat worth mentioning is the fact that the accuracy of lidar height measurements is largely dependent upon the accuracy of the lidar-derived DEM. The DEM used in this study exhibited higher errors in forests with dense canopies (Evans and Hudak, 2007), as would be expected, suggesting another source of uncertainly influencing lidar-derived tree height measurements. Without conducting a detailed total station survey, it is next to impossible to precisely quantify errors associated with inaccurate field measurements (tree location, tree height, and GPS measurements) and lidar-derived DEMs.

In terms of tree crown diameter, the goodness-of-fit statistics indicate that the VWF algorithm was slightly more accurate than the SWA algorithm when considering all 120 trees analyzed in this study (RMSE difference $=10 \mathrm{~cm}$ ). However, both VWF and SWA crown diameter measurements were poorly correlated with field measurements. Although the means of SWA and VWF crown diameter measurements were equivalent to the mean field-based crown diameter in some canopy cover strata, the pairwise tree crown diameter measurements were not within $25 \%$ of the field measurements across all canopy cover conditions. Furthermore, the SWA and VWF crown diameter measurements were extremely variable in all canopy cover strata. The relatively poor performance of the SWA algorithm can be attributed to tree proximity, as previously discussed in regard to tree detection. However, since the VWF algorithm predicts tree crown diameter as a function of tree height, the low accuracy of VWF crown diameter measurements is likely a result of the weak relationship between tree height and crown diameter across the Palouse Range study area. Furthermore, in forests with many different tree species, the accuracy of the VWF method decreases (see Figure 3). Since SWA does not require empirical, site-specific allometry data, it is more suited than VWF for measuring tree crown diameters where no empirical data exist, or where the relationship between tree height and crown diameter is weak. However, it is also worth noting that the accuracy of the SWA algorithm could vary depending upon tree species. For example, in its current implementation, SWA searches for objects that are similar in shape to the 2D Mexican hat wavelet, which closely approximates the shape of most trees across the Palouse Range. However, there are a few species, such as Pinus ponderosa, with crown morphology significantly different than the shape of the Mexican hat wavelet. In such situations, SWA may over- or underestimate tree crown diameter, or may fail to detect the tree altogether.

\section{Conclusions}

This study presents a rigorous assessment of how two automated tree detection algorithms perform across a full range of conifer canopy covers. The results presented herein demonstrate that increasing tree canopy cover has a significant negative impact upon the accuracy of both SWA and VWF tree measurements in a mixed-conifer forest. Although the two methods were statistically equivalent to field-based measurements when canopy cover was less than 50\%, neither method produced tree measurements within $25 \%$ of field-based measurements in dense canopy where cover was greater than $50 \%$. As a result, we suggest that both algorithms should be used cautiously at canopy cover greater than 50\%. Due to error propagation, this is especially true when using the SWA- or 


\section{Pagination not final/Pagination non finale}

Vol. 34, Suppl. 2, 2008

VWF-derived height and crown diameter measurements to estimate other tree parameters such as stem DBH or biomass.

It is worth pointing out that the forests of the Palouse Range are highly variable in terms of species composition and canopy structure. Although the VWF algorithm has been shown to perform better in areas where there is a strong relationship between tree height and crown diameter (Popescu, 2007), it is necessary to refine tree detection and measurement algorithms to (in the case of VWF) perform better where this height-crown diameter allometry is highly species-specific, or to (in the case of SWA) more effectively use the vertical dimension in delineating individual trees via lidar data.

In addition to improving individual tree detection and measurement algorithms, future research should be conducted to precisely quantify potential sources of error and uncertainty when measuring individual trees with lidar data. Specifically, such research should focus upon investigation of the influences lidar-derived DEM errors and field measurement errors have upon the accuracy of individual tree detection techniques.

\section{Acknowledgements}

This research was funded through the Sustainable Forestry Initiative of Agenda 2020, which is a joint effort of the USDA Forest Service Research \& Development and the American Forest and Paper Association. Partial funding for this work was also provided by the National Aeronautics and Space Administration (NASA) Synergy Program, the USDA Forest Service Rocky Mountain Research Station (04-JV-11222063299), and the Forest Public Access Resource Center (ForestPARC), an Upper Midwest Aerospace Consortium (UMAC) group, which is in turn supported with funds from NASA.

\section{References}

Asner, G.P., Archer, S., Hughes, R.F., Ansley, R.J., and Wessman, C.A. 2003. Net change in regional woody vegetation cover and carbon storage in Texas Drylands, 1937-1999. Global Change Biology, Vol. 9, pp. 316-335.

Biggs, P.H. 1991. Aerial tree volume functions for eucalypts in WesternAustralia. Canadian Journal of Forest Research, Vol. 21, pp. 1823-1828.

Chen, Q., Baldocchi, D., Gong, P., and Kelly, M. 2006. Isolating individual trees in a savanna woodland using small footprint LiDAR data. Photogrammetric Engineering and Remote Sensing, Vol. 72, No. 8, pp. $923-932$.

Chubey, M.S., Franklin, S.E., and Wulder, M.A. 2006. Object-based analysis of IKONOS-2 imagery for extraction of forest inventory parameters. Photogrammetric Engineering and Remote Sensing, Vol. 72, No. 4, pp. 383-394.

Clark, M.L., Clark, D.B., and Roberts, D.A. 2004. Small-footprint LiDAR estimation of sub-canopy elevation and tree height in a tropical rain forest landscape. Remote Sensing of Environment, Vol. 91, No. 1, pp. 68-89.

Crookston, N.L., and Dixon G.E. 2005. The forest vegetation simulator: a review of its structure, content and applications. Computer and Electronics in Agriculture, Vol. 49, pp. 60-80.
Evans, J.S., and Hudak, A.T. 2007. A multiscale curvature algorithm for classifying discrete return lidar in forested environments. IEEE Transactions on Geoscience and Remote Sensing, Vol.45, No.4, pp.1029-1038.

Falkowski, M.J., Gessler, P.E., Morgan, P., Hudak, A.T., and Smith, A.M.S. 2005. Characterizing and mapping forest fire fuels using ASTER imagery and gradient modeling. Forest Ecology and Management, Vol. 217, Nos. 23, pp. 129-146.

Falkowski, M.J., Smith, A.M.S., Hudak, A.T., Gessler, P.E., Vierling, L.A., and Crookston, N.L. 2006. Automated estimation of individual conifer tree height and crown diameter via two-dimensional spatial wavelet analysis of lidar data. Canadian Journal of Remote Sensing, Vol. 32, No. 1, pp. 153161.

Fensham, R.J., Fairfax, R.J., Holman, J.E., and Whitehead, P.J. 2002. Quantitative assessment of vegetation structural attributes from aerial photography. International Journal of Remote Sensing, Vol. 23, pp. $2293-$ 2317.

Fournier, R.A., Edwards, G., and Eldridge, N.R. 1995. A catalogue of potential spatial discriminators for high spatial resolution digital images of individual crowns. Canadian Journal of Remote Sensing, Vol. 21, pp. 285- 298.

Gaveau, D.L.A., and Hill, R.A. 2003. Quantifying canopy height underestimation by laser pulse penetration in small-footprint airborne laser scanning data. Canadian Journal of Remote Sensing, Vol. 29, No. 5, pp. 650-657.

Garrity, S.R., Vierling, L.A., Smith, A.M.S., Falkowski, M.J., and Hann, D.B. 2008. Automatic detection of shrub location, crown area, and cover using spatial wavelet analysis and aerial photography. Canadian Journal of Remote Sensing, Vol. 34, Suppl. 2. This issue.

Gougeon, F.A. 1995. Comparison of possible multispectral classification schemes for tree crowns individually delineated on high spatial resolution MEIS images. Canadian Journal of Remote Sensing, Vol. 21, No. 1, pp. 1-9.

Greenberg, J.A., Dobrowski, S.Z., Ramirez, C.M., Tull, J.L., and Ustin, S.L. 2006. A bottom-up approach to vegetation mapping of the Lake Tahoe Basin using hyperspatial image analysis. Photogrammetric Engineering and Remote Sensing, Vol. 72, No. 5, pp. 581-589.

Hagan, G.H., and Smith, J.L. 1986. Predicting tree groundline diameter from crown measurements made on 35-MM aerial-photography. Photogrammetric Engineering and Remote Sensing, Vol. 52, pp. 687-690.

Helms, J.A. (Editor). 1998. Dictionary of forestry. Society of American Foresters, Bethesda, MD. 210 pp.

Hyyppä, J., Olavi, K., Lehikoinen, M., and Inkinen, M. 2001. A segmentationbased method to retrieve stem volume estimates from 3-D tree height models produced by laser scanners. IEEE Transactions on Geoscience and Remote Sensing, Vol. 39, No. 5, pp. 969-975.

Leckie, D., Gougeon, F., Hill, D., Quinn, R., Armstrong, L., and Shreenan, R. 2003. Combined high-density LiDAR and multispectral imagery for individual tree crown analysis. International Journal of Remote Sensing, Vol. 29, No. 5, pp. 633-649.

Maltamo, M., Mustonen, K., Hyyppä, J., and Yu, X. 2004. The accuracy of estimating individual tree variables with airborne laser scanning in a boreal nature reserve. Canadian Journal of Forest Research, Vol. 34, pp. 17911801.

McRoberts, R.E., Nelson, M.D., and Wendt, D.G. 2002. Stratified estimation of forest area using satellite imagery, inventory data, and the $k$-nearest neighbors technique. Remote Sensing of Environment, Vol. 82, pp. 457468 . 


\section{Pagination not final/Pagination non finale}

Canadian Journal of Remote Sensing / Journal canadien de télédétection

Palace, M.K., Keller, M., Asner, G.P., Hagen, S.P, and Braswell, B. 2008. Amazon forest structure from IKONOS satellite data and the automated characterization of forest canopy properties. Biotropica, Vol. 42, No. 2, pp. 141-150.

Palenichke, R.M., and Zaremba, M.B. 2007. Multiscale isotropic matched filtering for individual tree detection in LiDAR images. IEEE Transactions on Geosciences and Remote Sensing, Vol. 45, No. 12, pp. 3944-3956.

Persson, A., Holmgren, J., and Söderman, U. 2002. Detecting and measuring individual trees using an airborne laser scanner. Photogrammetric Engineering and Remote Sensing, Vol. 68, No. 9, pp. 925-932.

Pocewicz, A., Gessler, P.E., and Robinson, A.P. 2004. The relationship between effective leaf area index and Landsat spectral response across elevation, solar insolation, and spatial scales in a northern Idaho forest. Canadian Journal of Forest Research, Vol. 34, pp. 465-480.

Popescu, S.C. 2007. Estimating biomass of individual pine trees using airborne lidar. Biomass and Bioenergy, Vol. 31, No. 9, pp. 646-655.

Popescu, S. 2008. Lidar TreeVaW [online]. Available from http://wwwssl.tamu.edu/personnel/s_popescu/TreeVaW/ [cited 18 February 2008].

Popescu, S.C., and Wynne, R.H. 2004. Seeing the trees in the forest: using lidar and multispectral data fusion with local filtering and variable window size for estimating tree height. Photogrammetric Engineering and Remote Sensing, Vol. 70, pp. 589-604.

R Development Core Team. 2007. R: a language and environment for statistical computing. R Foundation for Statistical Computing, Vienna, Austria. URL: http://www.R-project.org.

Robinson, A.P., Duursma, R.A., and Marshall, J.D. 2005. A regression-based equivalence test for model validation: shifting the burden of proof. Tree Physiology, Vol. 25, pp. 903-913.

Robinson, A. 2007. Equivalence R package version 0.4.3.

Solberg, S., Nasset, E., and Bollandas, O.M. 2006. Single tree segmentation using airborne laser scanner data in a structurally heterogeneous spruce forest. Photogrammetric Engineering and Remote Sensing, Vol. 72, No. 12, pp. 1369-1378.

Spurr, S.H. 1948. Aerial photographs in forestry. Ronald Press Company, New York. 348 pp.

Smith, A.M.S., Strand, E.K., Steele, C.M., Hann, D.B., Garrity, S.R., and Falkowski M.J. 2008. Production of vegetation spatial-structure maps by perobject analysis of juniper encroachment in multitemporal aerial photographs. Canadian Journal of Remote Sensing, Vol. 34, Suppl. 2. This issue.

Strand, E.K., Smith, A.M.S., Bunting, S.C., Vierling, L.A., Hann, D.B., and Gessler, P.E. 2006. Wavelet estimation of plant spatial patterns in multitemporal aerial photography. International Journal of Remote Sensing, Vol. 27, Nos. 9-10, pp. 2049-2054. doi:10.1080/01431160500444764.

Strand, E.K., Vierling, L.A., Smith, A.M.S., and Bunting, S.C. 2008. Net changes in aboveground woody carbon stock in western juniper woodlands, 1946-1984. Journal of Geophysical Research, Vol. 113, pp. G01013. doi:10.1029/2007JG000544.

USDA Forest Service. 2008. GPS information and receiver performance reports. Available from http://www.fs.fed.us/database/gps/gpsusfs.htm [cited 4 June 2008].

Wang, L., Gong, P., and Biging, G.S. 2004. Individual tree-crown delineation and treetop detection in high-spatial-resolution aerial imagery. Photogrammetric Engineering and Remote Sensing, Vol. 70, pp. 351-357.
Wellek, S., 2003. Testing statistical hypotheses of equivalence. Chapman \& Hall, London.

Wulder, M.A., White, J.C., Niemann, K.O., and Nelson, T. 2004. Comparison of airborne and satellite high spatial resolution data for the identification of individual trees with local maxima filtering. International Journal of Remote Sensing, Vol. 25, pp. 2225-2232.

Zagalikis, G., Cameron, A.D., and Miller, D.R. 2005. The application of digital photogrammetry and image analysis techniques to derive tree and stand characteristics. Canadian Journal of Forest Research, Vo 153 ,No. 5, pp. 1224-1237. 